Revue bibliographique pour le domaine irano-aryen

\title{
Daniel T. Potts. "Arboriculture in Ancient Iran: Walnut (Juglans regia), plane (Platanus orientalis) and the "Radde dictum""
}

\section{Sébastien Gondet}

\author{
(2) OpenEdition \\ Journals \\ Édition électronique \\ URL : http://journals.openedition.org/abstractairanica/48582 \\ DOI : 10.4000/abstractairanica.48582 \\ ISBN : 1961-960X \\ ISSN : 1961-960X \\ Éditeur : \\ CNRS (UMR 7528 Mondes iraniens et indiens), Éditions de l'IFRI
}

\section{Référence électronique}

Sébastien Gondet, «Daniel T. Potts. "Arboriculture in Ancient Iran: Walnut (Juglans regia), plane (Platanus orientalis) and the "Radde dictum"'” », Abstracta Iranica [En ligne], Volume 40-41 | 2019, document 7, mis en ligne le 30 octobre 2019, consulté le 26 avril 2021. URL : http://

journals.openedition.org/abstractairanica/48582 ; DOI : https://doi.org/10.4000/abstractairanica 48582

Ce document a été généré automatiquement le 26 avril 2021.

Tous droits réservés 


\title{
Daniel T. Potts. "Arboriculture in Ancient Iran: Walnut (Juglans regia), plane (Platanus orientalis) and the "Radde dictum""
}

\author{
Sébastien Gondet
}

\section{RÉFÉRENCE}

Daniel T. Potts. “Arboriculture in Ancient Iran: Walnut (Juglans regia), plane (Platanus orientalis) and the "Radde dictum"", DABIR, 6, 2018, p. 101-109

1 Comme le veut le format de la revue en ligne DABIR, cet article propose une synthèse courte mais très complète s'appuyant sur une bibliographie admirablement riche et variée. Elle traite de la culture du platane et du noyer dans le Monde iranien, deux espèces économiquement et symboliquement très importantes qui pourraient être originaires des régions du nord-ouest de l'Iran. Les sources mobilisées par l'A. prennent également en compte des données mésopotamiennes.

2 Nos connaissances concernant l'apparition et la diffusion de l'arboriculture du platane et du noyer ont été profondément renouvelées par des données palynologiques parues depuis les années 1980, avec une accélération depuis la fin des années 2000, et obtenues grâce à l'analyse d'archives sédimentaires prélevées dans plusieurs lacs de l'ouest et du centre de l'Iran. L'A. croise ces données avec celles de nombreuses sources textuelles et archéologiques pour retracer à grands traits l'histoire du développement de ces deux espèces sylvicoles. Remontant au tournant des $3^{\mathrm{e}}$ et $2^{\mathrm{e}}$ millénaires, cette arboriculture a connu plusieurs phases de développement postérieures, suivant des cycles distincts en fonction des régions, ce jusqu'aux débuts de l'ère islamique. Comme l'avaient déjà suggéré nombre d'érudits et de botanistes des $\mathrm{XVIII}^{\mathrm{e}}$ et $\mathrm{XIX}^{\mathrm{e}}$ s., en particulier l'Allemand Gustav Radde cité dans le titre et dont les écrits ont inspiré cet article à l'A., 
l'Iran constitue certainement un foyer majeur de culture du noyer et du platane dès les époques reculées de l'Age du bronze.

\section{AUTEURS}

\section{SÉBASTIEN GONDET}

UMR 5133 CNRS-Université de Lyon 